Tarih Kültür ve Sanat Araştırmaları Dergisi

Revue des Recherches en Histoire Culture et Art

$$
\text { مجلة البحوث التاريخية و الثقافية والفنية }
$$

Vol. 6, No. 5, November 2017

Copyright (C) Karabuk University

http://kutaksam.karabuk.edu.tr

\title{
DOI: 10.7596/taksad.v6i5.1280
}

Citation: Beloedova, A., Khukhryanskaya, N., Novinkina, E., Pitinova, M., \& Shatalova, Y. (2017). Representation of Femininity: Grammatical Aspect (Cosmopolitan, Marie Claire and Glamour Magazines). Journal of History Culture and Art Research, 6(5), 200-206. doi:http://dx.doi.org/10.7596/taksad.v6i5.1280

\section{Representation of Femininity: Grammatical Aspect (Cosmopolitan, Marie Claire and Glamour Magazines)}

\author{
Anna V. Beloedova ${ }^{1}$, Nadezhda N. Khukhryanskaya ${ }^{2}$, Ekaterina A. Novinkina ${ }^{3}$, \\ Marina Yu. Pitinova ${ }^{4}$, Yuliya N. Shatalova ${ }^{5}$,
}

\begin{abstract}
The paper features the language objectivation of femininity in the glossy magazines Cosmopolitan, Marie Claire and Glamour. The analysis of the problem is based on the theory of the social construction of gender and aims to identify the main trends of language representation of women. The material of the study was Russian Publications Cosmopolitan, Marie Claire and Glamor - the most popular glossy magazines designed for women. The files of the examples analyzed by us are compiled by the method of continuous sampling (more than 2000 contexts) on the basis of printed and Internet versions of Cosmopolitan, Marie Claire and Glamor journals in 2016. The verbal component is considered as one of the main factors in the construction of gender in glossy magazines, which model new type of the "femine" consciousness, combining the sensual experience of reality and the ability to transform it. Gender relations, stereotypes and ideology are revealed through the analysis of linguistic representations. The authors observe morphological and syntax means of the Russian language as indicators of gender identification in terms of mediatext construction. The analysis of language means proves the complication of gender identification in Cosmopolitan, Marie Claire and Glamour, and the sharpening of the "femine" consciousness due to inclusion of masculine features in it. The analysis of linguistic means representing femininity allows to draw a conclusion about the modeling a new type of "female consciousness" on the pages of glossy magazines, in which the ability to the sensual experience of reality is supplemented by the ability to transform it.
\end{abstract}

Keywords: Gender, Mass media, Glossy magazine, Femininity, Media linguistics.

\footnotetext{
${ }^{1}$ Belgorod State University, 85 Pobedy Street, Belgorod, the Belgorod region, 308015, Russia. E-mail: beloedova@bsu.edu.ru

${ }^{2}$ Belgorod State University, 85 Pobedy Street, Belgorod, the Belgorod region, 308015, Russia.

${ }^{3}$ Belgorod State University, 85 Pobedy Street, Belgorod, the Belgorod region, 308015, Russia.

${ }^{4}$ Belgorod State University, 85 Pobedy Street, Belgorod, the Belgorod region, 308015, Russia.

${ }^{5}$ Belgorod State University, 85 Pobedy Street, Belgorod, the Belgorod region, 308015, Russia.
} 


\section{Introduction}

When they start to consider gender issues in the context of mass media functioning, one should turn to the theory of gender social development. Within the framework of this theory, gender is presented as an organized model of social relations between sexes, defining their interpersonal and family relationships, as well as the interaction in the main institutions of society. The problem of gender designing is multifaceted one, as this activity is carried out through the institutions of socialization, the division of labor, the system of gender roles, the family, the media, as well as during the adoption of society norms and roles set by an individual and the development of their line of behavior in accordance with them. The technologies of gender development are aimed at the assimilation of gender norms, which in many ways predetermine the models of relations in a particular society.

The mass media content demonstrates the whole set of gender issue main aspects: the gender ideology (the view about the qualities preferred for men and women existing in society, the difference and similarity between them), gender stereotypes (the patterns on the differences between a man and a woman, prescribing to behave in accordance with the rules developed for genders), gender roles (gender permeates all situational roles), gender identity (the identification with a certain gender, the mastery of rules and norms typical for him, their demonstration in his behavior), gender stratification (two sexes occupy an unequal position in society, as a rule, men have the advantage). The angle and the sign of these aspects consideration are the product of the policy pursued in various cultures and societies towards men and women.

The visual possibilities of mass media in the aspect of reproduction and the strengthening of the gender world symbolic images are endless, however, the verbal component also acts as one of the main factors for the construction of gender in mass media. Gender-typical behavior in any situation of interaction is reinforced by the discursive structure of speech.

Nowadays, the researchers in the field of the interrelation between language and gender are primarily interested in the possibilities of media texts as a platform for the expression and dissemination of gender images, stereotypes and ideology (Caldas-Coulthard, \& Milani, 2016: 145). From this point of view, the following issues are relevant: the way women and men are represented in media texts (for example, passive or active, in certain roles and activities); there is femininity and masculinity, and the character of gender relations in media texts (Caldas-Coulthard, \& Milani, 2016; Ehrlich, Meyerhoff, \& Holmes, 2014; Hellinger \& Motschenbacher, 2015; Litosseliti, 2013; LoCastro, 2012; Motschenbacher, 2016).

Modern Russia speaks the language of mass media, therefore, the reality of mass media must be realized in all its manifestations, in all its grammars (social, cultural, cognitive and communicative) that determine the character of speech, discursive and cultural-symbolic behavior of a person.

The object of our study is represented by the features of femininity linguistic objectification as a paradigmatic form of linguistic consciousness. Grammatical means that objectify the semantic space of femininity in glossy magazines as a special type of consciousness act as the subject of research.

\section{Material and Methods}

The material of the study was Russian Publications Cosmopolitan, Marie Claire and Glamor - the most popular glossy magazines designed for women. The files of the examples analyzed by us are compiled by the method of continuous sampling (more than 2000 contexts) on the basis of printed and Internet versions of Cosmopolitan, Marie Claire and Glamor journals in 2016.

The leading research method of our work is semantic-cognitive method. The methods of cognitive linguistics have been developed on its basis, which allow us to discover the features not only of national 
but also of group thinking and the entire diversity of individual author's conceptospheres (Popova, \& Sternin, 2006: 13).

The method of contextual analysis, focused on the identification of the linguistic and the semantic environment role in the development of the unit in question value, allows us to determine the meaning of used linguistic means and the nature of the semantic collocation.

Observation method as a general scientific method based on direct perception and generalization of the objective manifestations of this phenomenon allows us to see the studied phenomenon in all its fullness and diversity of its manifestations, to identify and fix its qualitative features. Observation of a text and its aggregations "includes the attention to the language basis of acquired impressions" (Bolotnova, 2007: 415), thereby providing understanding of linguistic means selection principles.

The statistical method ensures the detection of textual regularities on the basis of quantitative characteristics obtaining.

\section{Results and Discussion}

The understanding of glossy magazines as a segment of modern media discourse, which claims today to be the most important developer and provider of ideological-content, spiritual, moral and stylisticaesthetic forms as the social standards that receive serious ideological support from the committed subjects of the social sphere is important for the study (Polonsky, \& Samotuga, 2010: 228).

Gender as a cultural and symbolic sex is not actually a linguistic category, however its content can be uncovered through the analysis of linguistic representations, which explains the relevance of linguistic research today aimed at the revealing of the features in this aspect of collective consciousness. Studies show that in most cases it is advisable to talk not about the rigid laws of speech-thinking representation between men and women, but only about significant trends. Women and men certainly operate differently by linguistic meanings fixed in the collective consciousness without taking into account the form of their representation (conceptual, figurative, symbolic one).

The following groups of gender identification can be distinguished at different language levels: phonetic tone pitch, voice timbre, intonation, pause, etc.; morphological - the predominant use of certain parts of speech and word forms; lexical ones - the use of words that name a man or a woman or contain the semantic component of "femininity" or "muscularity" in meaning; stylistic - the predominant use of words and structures characteristic of male or female speech (Kayumova, 2012; Kirilina, 2000; Oschepkova, 2001; Popova, 2007; Samotuga, 2012; Treschalina, 1998).

In the study we attempted to identify the features of "female consciousness" representation by the means of Russian language, taking into account the frequency of certain parts of speech use as one of the gender identification signs. Within the framework of morphological and syntactic levels, the frequency of independent, service parts of speech and syntactic constructions use in the texts of the magazines "Cosmopolitan", "Marie Claire" and "Glamor" was considered, which allowed us to reveal some of their patterns and features.

The analysis of the texts in Cosmopolitan, Marie Claire, and Glamor magazines shows that nouns predominate in the general lexeme fund, calculated by us on the basis of a representative sample. The use of a large number of nouns in the journal texts is explained by the desire to focus on the subject, which as we know is characteristic of female consciousness. Let's note that we found a large number of nouns: concrete (man, woman, friend, girlfriend, house, family, body, dress, lipstick, etc.) and abstract (beauty, constancy, happiness, faithfulness, will, destiny, pleasure, mood, positivity, naivety, nature) ones: "The organization of weddings is a cycle of happiness in nature" (Cosmopolitan, February, 2016), "The 
New Year is the best time to unleash your fashionable imagination!" (Cosmopolitan, November, 2016). Among the abstract vocabulary, the subjectively psychological vocabulary (love, fidelity, happiness, betrayal) is clearly distinguished, which, according to the researchers, is a sign of rather female language consciousness, and rational-logical vocabulary (mind, knowledge, career, talent) that represents rather male language consciousness.

A special place in the texts of the glossy magazines under consideration is occupied by adjectives with a positive assessment (unique, romantic, pleasant, beautiful, fervent, brave, sociable, beloved, dear, cheerful, courageous, happy, beautiful, smart, young, tender, bright, etc.). Their high quantitative indicator shows the development of female consciousness stereotype, aimed at sympathy, care and delight: "Discover the feeling of deep hydration. The northern approach to beauty is based on the magic of the unique solar cycle of the Arctic ..." (Glamor, December, 2016).

In the course of the study they established that the mark of female language consciousness is the tendency to the objectification of meanings through a verb. He does not just provide dynamism to the text, prompting for action, but is a sign of a personality, committing the actions. Such active verbs as to build, to talk, to know, to think, to do, to love, to meet, to feel, to read, to try, to wear, etc., dominate in the analyzed media texts: "It's time to go on a fascinating journey together, to think about the future and about how to make your life together more beautiful!" (Cosmopolitan, May, 2016), "Personally, I'm going to study the advice of experts, to say goodbye to my inferiority complex and start enjoying both my career and my life" (Glamor, December, 2016). The use of verbs in such numbers and the relevance of their semantics indicate that gender identification in the magazines Cosmopolitan, Marie Claire and Glamor becomes more complicated, since there is a mixture of typically female and male.

A characteristic feature of the texts concerning the journals in question is an active use of imperative mood of a verb. Often, editorial materials are built as a set of tips, each of which is represented by an imperative design: "Eliminate negative bias", "Be happy as long as possible", "Produce endorphins", "Try not to let negative things through yourself" (Cosmopolitan, March, 2016).

The characteristics of the target audience of the publication determine the choice of addressing form to readers - a formal or a familiar addressing. Glamor and Marie Claire magazines use the verb forms of the 2nd person plural (a polite form of addressing), for example: "Watch the level of skin hydration", "Reduce sweets to a minimum", (Glamor, October, 2016); "Do not rush to spend this luxury on trifles", "Carry out the audit of lost hopes" (Marie Claire, November, 2016). In the "Cosmopolitan" magazine verbal forms realize a familiar form of addressing, which creates the atmosphere of friendly conversation, a confidential conversation: "Think about the weather improvement in the office", (Cosmopolitan, June, 2016); "Learn to listen to others", "Develop a sense of speech and creative thinking, try yourself in theatrical criticism, journalism and literature" (Cosmopolitan, June, 2016).

Quite often pronouns are used in the texts of journals. In the contexts under study, the possessive and personal pronouns of the second person singular are in the first place in terms of the number of uses. Their use allows you to reduce the officiality and create a more trusting atmosphere: "Were you trying to select convenient and practical images for every day all year round?" (Cosmopolitan, November, 2016), "A man says that he loves you, and you understand in terror that you are not ready yet say "And I love you too" (Cosmopolitan, May, 2016).

Adverbs, mostly subjective-valued, are designed to strengthen and supplement the positive assessment: "The jewelry of white gold with pearls ... reflect the style of that time, therefore they look really luxurious and majestic" (Glamor, December, 2016).

The pages of the magazines Cosmopolitan, Marie Claire, and Glamor have a large number of diminutives - 
diminutive forms of nouns and adjectives, which, as is known, is an identification sign of the linguistic consciousness of a woman: "... She uploads to Instagram the snapshot of a short down-padded coat, a sky-blue one and with white clouds floating on it bought at the store Kixbox" (Marie Claire, February 2016).

Interjections act as the expression of emotional reactions to the surrounding reality and are characteristic female expressions: "Hey, everything is okay" (Glamor, October, 2016), "Hey, serious lady! Yes, I addressed to you (Glamor, June, 2016), "Going to Norway? There are fjords, rocks and aurora borealis there ... And are there decent roads? "Oh, yes!" (Cosmopolitan, February, 2016).

It should also be noted that in the development of feminine gender, the syntactic level of the language is involved. The syntax of modern publications in women magazines has the features that largely reflect female oral speech and which are associated with the use of emotionally expressive constructions (Popova, 2007: 44-45).

One of the most frequent methods of text expression is the use of exclamation sentences: "What a pleasure it is to be in the epicenter of events and watch the live emotions of winners and losers!", "There is a misconception that clothes cannot be cleaned from chewing gum. This is not so!" (Cosmopolitan, February, 2016), etc.

This method of expressive syntax is quite widely used in women magazine as parcelling. Parcelling, consisting in the deliberate dismemberment of the sentence into two or more syntactic units, makes it possible to isolate and strengthen the most important points of the utterance. In a lively conversation, these goals are achieved through pauses and intonation.

Parceled structures reflect the emotionality and discontinuity of the female manner of presentation. Let's give examples: "I do not regret my words. As well as about the initiative that she showed later" (Cosmopolitan, February, 2016); "Generation Y (as scientists call modern people at the age of 25 - 30 years) loves selfie, sleeps a little and works a lot. Almost like iPhones, but only alive. And also requiring recharging" (Marie Claire, July, 2016).

The analysis of the test material shows the widespread use of inserted structures, the use of which is also associated with the imitation of spontaneous oral speech. Using the insertion structures, any additional comments, clarifications and amendments are introduced concerning the content of the main proposal. The insertion structure can relate to the contents of the main sentence as a whole, for example: "... I was interested in the way our consciousness is changing with the advent of new, virtual forms of life and communication (which, by the way, is very consonant with the theme of Biennale - Young Art of this year "Deep inside"), "But soon either your opponents will understand that you are right, or new interesting people and exciting events will take place in your life (to meet changes in full splendor, study the material on page 48)" (Glamor, July, 2016). More often, however, an explanation, an additional information refers to any part of a statement: "Blue shimmering cream eye shadow shall be applied to your entire mobile eyelid with your finger (most conveniently the nameless) - thus you will avoid clear boundaries", "Social psychologist Doone Holman studying cancer problems is sure that many do not apply the means with SPF correctly (not enough and not often), but use them not for the intended purpose" (Glamor, June, 2016).

Inserted structures allow us to clarify the meaning of a term, a concept or a statement that may be unknown to a reader: "Eat the dishes from vegetables and fruits containing fiber (zucchini, tomatoes, apples, grapes), avoid spicy and fat food" (Cosmopolitan, June, 2016); "The storyteller de Lint and the artist Wess (known for his work on Geimann's "Star dust") are claimed as the co-authors of this story about the girl named Lillian, who became a cat for a time" (Glamor, June, 2016). Agreeing with the observations by E.R. Kayumova (2012: 149-150), we note that the explanation function for inserted 
structures is not the leading one in woman magazines.

An active use of dialogization methods is also a characteristic feature of modern female "gloss". Thus, the analysis of the material indicates a high frequency of question-answer unities: the author formulates the question (foreseeing the possible thoughts of the readers) and answers himself: "Do you think the next portion of the cake is dangerous only for the figure? The skin will also react to the abuse of sweets" (Cosmopolitan, April, 2016); "Do you think that you are not in your place, and perhaps you regret your decision? During the first months this is normal, then it is not" (Cosmopolitan, August, 2016).

Thus, the syntax of woman publications is largely focused on the imitation of spontaneous female speech and represents its expressive character.

\section{Conclusion}

The discourse of modern woman glossy magazines is the manifestation of gender-motivated language consciousness; it is a complex social-cultural phenomenon that arises from the creation of texts by female authors for female readers. At the level of woman magazine text morphology, the dominants of gender identification are an active use of nouns, adjectives and adverbs of positive evaluation, a large number of diminutives, interjections, which characterizes the female language consciousness. The syntax of media texts in many respects imitates woman's oral speech, which causes the use of expression methods: exclamation sentences, parcelling, inserted structures, question-answer units. At the same time, there is the increase in the use of means characteristic of the male language consciousness. This allows us to talk about the changes in the ways of gender identification modeling.

The language representation of femininity in the journals "Cosmopolitan", "Marie Claire" and "Glamor" testifies to the complication of gender identification, the shift of typically "female" and "male" consciousness towards the strengthening of "masculine". The analysis of linguistic means representing femininity allows to draw a conclusion about the modeling a new type of "female consciousness" on the pages of glossy magazines, in which the ability to the sensual experience of reality is supplemented by the ability to transform it.

\section{References}

Bolotnova, N. S. (2007). Philological analysis of the text. Moscow: Science.

Caldas-Coulthard, C. R. \& Milani, T. (2016). Ten Years of Gender and Language. Gender and Language, 10(2), 145-148.

Ehrlich, S.; Meyerhoff, M. \& Holmes, J. (Eds.) (2014). The Handbook of Language, Gender, and Sexuality $\left(2^{\text {nd }}\right.$ ed. $)$. Wiley Blackwell.

Hellinger, M. \& Motschenbacher, H. (eds.) (2015). Gender Across Languages: The linguistic representation of women and men.

Kayumova, E. R. (2012). Comparative analysis of linguistic peculiarities of female and male glossy magazines. Dissertation by the candidate of philology: 10.02.01. Sterlitamak. 
Kirilina, A. V. (2000). Gender aspects of language and communication. Dissertation of Philology Doctor. Moscow.

Litosseliti, L. (2013). Gender and Language: Theory and Practice. Routledge.

LoCastro, V. (2012). Language, Gender, and Power. Pragmatics for Language Educators: A Sociolinguistic Perspective. Routledge.

Motschenbacher, H. (2016). A discursive approach to structural gender linguistics: theoretical and methodological considerations. Gender and Language, 10(2), 149-169.

Oschepkova, E. S. (2001). Psychological features of men and women, manifested in written speech. Gender: language, culture, communication (pp. 279-289). Moscow.

Polonsky, A. V. \& Samotuga, E. A. (2010). Key features of glossy magazine discourse. Belgorod State University Scientific bulletin: Philology, Journalism, Pedagogy, Psychology, 18(89), 227-235.

Popova, E. A. (2007). On the peculiarities of men and women speech. Russian speech, 3, 40-49.

Popova, Z. D. \& Sternin, I. A. (2006). Semantic-cognitive analysis of language. Voronezh: Publishing House Origins.

Samotuga, E. A. (2012). Linguistic-stylistic features of gender representation in glossy magazines. Belgorod State University Scientific bulletin: Philology, Journalism, Pedagogy, Psychology, 6 (125), 154-163.

Treschalina, I. V. (1998). The language personality of the character in the prose by A.P. Chekhov during the $80 \mathrm{~s}$ and 90 s. Dissertation from the Candidate of philology. Tver. 